\section{- OPEN ACCESS}

\title{
Inhaled corticosteroids in COPD and the risk of serious pneumonia
}

\author{
Samy Suissa, Valérie Patenaude, Francesco Lapi, Pierre Ernst
}

Departments of Epidemiology and Biostatistics and of Medicine, Center for Clinical Epidemiology, Lady Davis Research Institute, Jewish General Hospital, McGill University, Montreal, Québec, Canada

\section{Correspondence to}

Prof Samy Suissa, Centre for Clinical Epidemiology, Jewish General Hospital, 3755 Cote Ste-Catherine, Montreal, Québec, Canada H3T 1E2; samy.suissa@mcgill.ca

Received 14 October 2012 Revised 16 August 2013 Accepted 25 August 2013

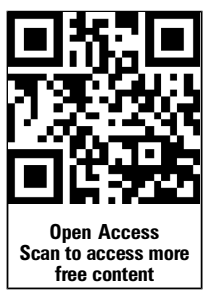

\section{SLinked}

- http://dx.doi.org/10.1136/ thoraxjnl-2012-202709

- http://dx.doi.org/10.1136/ thoraxjnl-2012-202959

To cite: Suissa $S$,

Patenaude V, Lapi F, et al.

Thorax 2013:68:

1029-1036.

\begin{abstract}
Background Inhaled corticosteroids (ICS) are known to increase the risk of pneumonia in patients with chronic obstructive pulmonary disease (COPD). It is unclear whether the risk of pneumonia varies for different inhaled agents, particularly fluticasone and budesonide, and increases with the dose and long-term duration of use. Methods We formed a new-user cohort of patients with COPD treated during 1990-2005. Subjects were identified using the Quebec health insurance databases and followed through 2007 or until a serious pneumonia event, defined as a first hospitalisation for or death from pneumonia. A nested case-control analysis was used to estimate the rate ratio (RR) of serious pneumonia associated with current ICS use, adjusted for age, sex, respiratory disease severity and comorbidity.

Results The cohort included 163514 patients, of which 20344 had a serious pneumonia event during the 5.4 years of follow-up (incidence rate 2.4/100/year). Current use of ICS was associated with a $69 \%$ increase in the rate of serious pneumonia (RR 1.69; $95 \%$ Cl 1.63 to 1.75). The risk was sustained with long-term use and declined gradually after stopping ICS use, disappearing after 6 months (RR 1.08; $95 \% \mathrm{Cl} 0.99$ to 1.17). The rate of serious pneumonia was higher with fluticasone (RR 2.01; 95\% Cl 1.93 to 2.10), increasing with the daily dose, but was much lower with budesonide (RR 1.17; 95\% Cl 1.09 to 1.26).

Conclusions ICS use by patients with COPD increases the risk of serious pneumonia. The risk is particularly elevated and dose related with fluticasone. While residual confounding cannot be ruled out, the results are consistent with those from recent randomised trials.
\end{abstract}

\section{INTRODUCTION}

Inhaled corticosteroids (ICS) are commonly used for the treatment of asthma and chronic obstructive pulmonary disease (COPD), though their effectiveness for the latter remains controversial. ${ }^{1}{ }^{2}$ Nevertheless, these drugs are now widely used in COPD and at high doses, with patients frequently receiving the equivalent of $1000 \mu \mathrm{g}$ of fluticasone per day. ${ }^{3}{ }^{4}$ High doses have been associated with significant systemic effects such as pneumonia, glaucoma, cataracts, adrenal suppression, accelerated bone turnover and diabetes. ${ }^{5-10}$

With respect to pneumonia, however, there remain uncertainties as to whether ICS all carry a similar increased risk and whether the effect is dose related. Meta-analysis of randomised trials reported significant increases of up to $70 \%$ in the risk of adverse pneumonia events associated with ICS, whether used alone or in combination with a long-acting $\beta$ agonist, with subgroup analyses suggesting that the risk is particularly

\section{Key messages}

What is the key question?

- Inhaled corticosteroids are known to increase the risk of developing pneumonia in patients with chronic obstructive pulmonary disease (COPD), but it is unclear whether this risk varies for different agents, particularly fluticasone and budesonide.

\section{What is the bottom line?}

- The risk of patients with COPD developing serious pneumonia is particularly elevated and dose related with fluticasone use and much lower with budesonide. While residual confounding cannot be ruled out, the results are consistent with those from recent randomised trials.

\section{Why read on?}

- The study comprised a large cohort of over 160000 patients with COPD followed for a mean of 5 years, during which over 20000 were hospitalised or died with a primary diagnosis of pneumonia. It shows that the risk of serious pneumonia, elevated with current use of inhaled corticosteroids, is sustained with long-term use but declines after discontinuation and disappears after 6 months.

elevated with high doses and shorter durations. ${ }^{11} 12$ Indeed, the 3-year TORCH and 2-year INSPIRE trials reported increases in pneumonia risk with fluticasone (1000 $\mu$ g per day) of $64 \%$ and $94 \%$, respectively, ${ }^{13} 14$ while another trial also found a threefold increase in the risk at this dose. ${ }^{15}$ Yet, two trials evaluating a lower dose of fluticasone ( $500 \mu \mathrm{g}$ per day) for 1 year also found close to a twofold higher incidence of pneumonia at 1 year with fluticasone. ${ }^{16-18}$ However, a pooled analysis of 7000 patients from several trials of budesonide found no increased risk of pneumonia over 1 year, ${ }^{19}$ while two meta-analyses suggest a lower risk for budesonide compared with fluticasone. ${ }^{20} 21$

We conducted a population-based cohort study of treated patients with COPD to assess whether the different ICS vary in their risk of pneumonia and to evaluate the dose-response effects.

\section{METHODS}

\section{Data source}

We used the computerised databases of the Régie de l'assurance maladie du Québec (RAMQ), the 
universal health insurance programme of the province of Québec, Canada, for its 7 million residents. The databases contain information on demographics and all medical services rendered for all residents of the Province. All deaths are in the Institut de la statistique du Québec (ISQ) database, containing the date of death and the underlying cause of death. The prescription drugs database includes outpatient prescription medications dispensed to all people aged 65 years or older, social welfare recipients and, since 1996, all other residents who opted to join the provincial drug plan, covering around half the population of Quebec. These databases have been used previously to conduct epidemiological studies of the risks of ICS. ${ }^{5}$ 9102223

\section{Study design}

The source population for this study consisted of all subjects who, between 1990 and 2005, were dispensed at least one prescription for any of the following respiratory medications: any form of $\beta$ agonist, theophylline, ipratropium or tiotropium bromide, and ICS. The study cohort of patients with COPD was formed by identifying all subjects with three or more prescriptions for these medications (except ICS) in any 1 year and on at least two different dates. To ensure a new-user COPD cohort, we included only those with no respiratory medications during the 2 years before the first of these three prescriptions. Subjects had to be at least 55 years old and have 1 year of drug coverage by the time of their third prescription. Subjects with a mention of asthma, either as primary or secondary diagnosis during a hospitalisation, or using nedocromil, ketotifen, cromolyn or antileukotrienes, were excluded. All subjects in the cohort were followed from cohort entry, taken as the date of the third prescription, until the first hospitalisation for pneumonia, death, end of RAMQ drug coverage, or 31 March 2007. In view of the large size of the cohort and the time-varying nature of ICS prescriptions, a nested case-control analysis within the cohort was performed.

\section{Pneumonia cases and controls}

Cases of serious pneumonia were defined as a hospitalisation for or death from pneumonia. The first hospitalisation with an admission or primary diagnosis of pneumonia of any cause, including influenza, was identified in the RAMQ hospitalisation database (International Classification of Diseases (ICD)-9 codes 480-487.0, ICD10 codes J10.0, J11.0, J12-J18) during cohort follow-up. For outpatients, deaths with pneumonia as a principal cause were identified. The date of admission or outpatient death was called the index date.

For each case, 10 controls matched on the case's age within 1 year and cohort entry month were selected at random from all subjects without the outcome of interest on the case's event date (index date). For the few cases with no eligible controls, the age and calendar time matching criteria were relaxed to within 5 years and the same year, respectively. When less than 10 potential controls were available for a case, all members of the risk set were included as controls for that case.

\section{ICS exposure}

All prescriptions for ICS, alone or in a combination inhaler, dispensed between cohort entry and the index date were identified. These include inhaled beclomethasone, fluticasone, budesonide, triamcinolone and flunisolide. All doses of ICS were converted to fluticasone-equivalent doses on the basis of relative topical potency and what experts consider to be comparable doses according to the National Asthma Education Expert Panel report
Figure 1 Flowchart of cohort formation.

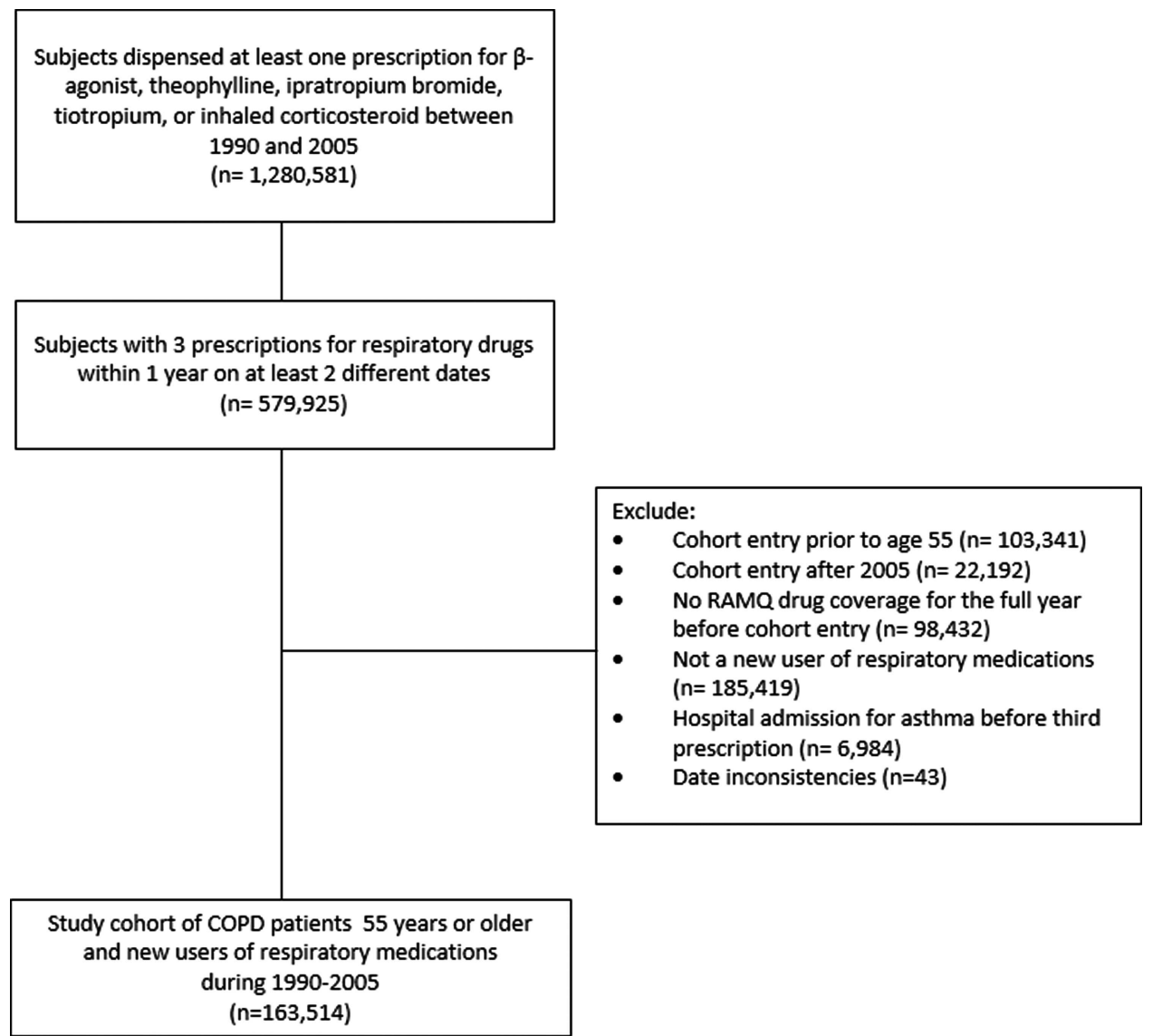


2 (see figure $3-5 \mathrm{~b}$ and $3-5 \mathrm{c}$ in that report) and the Canadian asthma consensus statement (see table 8 in that statement). ${ }^{24} 25$ Dose equivalences used are beclomethasone $100 \mu \mathrm{g}$, budesonide $80 \mu \mathrm{g}$, triamcinolone $200 \mu \mathrm{g}$, fluticasone $50 \mu \mathrm{g}$ and flunisolide $200 \mu \mathrm{g}$. The converted doses were categorised as high (fluticasone $1000 \mu \mathrm{g} /$ day or more), moderate (500-999 $\mu \mathrm{g} /$ day) and low (less than $500 \mu \mathrm{g} /$ day). The duration of continuous ICS use was calculated for current users as the time from the first prescription until the index date, with continuous use defined by a utilisation rate $\geq 0.5$ prescription per month.

\section{Data analysis}

The rates of serious pneumonia were estimated and their 95\% CIs computed using the Poisson distribution. Crude and adjusted RRs of serious pneumonia associated with current ICS use with 95\% CIs were estimated by conditional logistic regression to account for the matching of cases and controls. The RRs were adjusted for age (matched by design), sex, severity of respiratory disease, and other conditions associated with a risk of pneumonia. Severity of respiratory disease was measured by the number of prescriptions for $ß$ agonists, ipratropium and tiotropium bromide, theophylline, cromolyns, oral corticosteroids and antibiotics, the presence of a hospitalisation with a primary diagnosis of COPD, all measured in the year prior to the index date. We excluded antibiotic prescriptions in the 30 days prior to the index date since it could represent initial therapy for the pneumonia under study. Comorbidity included cardiac disease defined by a prescription for cardiotropes, antihypertensives, diuretics or vasodilators; diabetes defined by insulin or oral hypoglycaemic agents; central nervous system drugs included benzodiazepines, major tranquillizers, anticonvulsants and drugs for parkinsonism; osteoporosis drugs included calcium, vitamin D and biphosphonates; antirheumatic drugs included gold salts, methotrexate, azathioprine, hydroxychloroquine and chloroquine. Non-steroidal anti-inflammatory drugs, antidepressive agents and narcotics were considered as separate categories.

Subjects were considered current ICS users if the last prescription was dispensed within 60 days of the index date and non-use during the entire prior year was used as the reference category. Subjects whose last prescription was dispensed between 61 and 365 days prior to the index date were classified as past users. Current ICS users were also classified as users of fluticasone, budesonide or other ICS (beclomethasone, flunisolide or triamcinolone). Dose-response was assessed using the fluticasone-equivalent daily dose of current users classified as high, moderate and low. It was further analysed by modelling the actual current fluticasone-equivalent daily dose continuously using cubic splines models. These models fit the dose-response curve using a cubic polynomial function separately within four mutually exclusive dose intervals, then imposing that the curves join at boundaries to generate a smooth continuous doseresponse function. Duration of ICS use, for current users with a utilisation rate $\geq 0.5$ per month, was also modelled with cubic splines.

A sensitivity analysis was performed by stratifying by prior COPD hospitalisation to address the possible inaccuracy of the COPD definition of our cohort and the fact that budesonide was most likely used more frequently for asthma in Quebec at the time of this study. This is because, while neither budesonide nor fluticasone was indicated for use in COPD, the fluticasonesalmeterol combination was approved and therefore promoted for COPD during the time period under study while the budesonide-formoterol combination was not. All analyses were conducted using SAS V.9.2.
We obtained ethics approval for this study from the Research Ethics Committee of the Jewish General Hospital, Montreal, Quebec, Canada.

\section{RESULTS}

The study cohort included 163514 patients with COPD treated with respiratory medications (figure 1). At cohort entry, the patients were 72 years of age and $50 \%$ were men. The mean duration of follow-up was 5.4 years, during which 20344 patients were identified as having serious pneumonia, including 19667 hospitalised for pneumonia and 677 who died of pneumonia as outpatients, after a mean 4.2 years, for an overall incidence rate of serious pneumonia of 2.4 per 100 per year. Cases of serious pneumonia and their matched controls were around 78 years of age at the index date and the average time from cohort entry to pneumonia was 4.2 years (table 1 ). The cases had more severe respiratory disease, with more prescriptions for respiratory drugs, including oral corticosteroids and antibiotics. The cases had a slightly higher prevalence of comorbidity. Table 2 compares these characteristics among the controls according to the current use of fluticasone and budesonide, showing that users of fluticasone were more likely to have been previously hospitalised for pneumonia and COPD than

Table 1 Characteristics of cases of hospitalised or fatal pneumonia and their matched controls selected from a cohort of patients with COPD

\begin{tabular}{|c|c|c|}
\hline & $\begin{array}{l}\text { Pneumonia } \\
\text { cases }\end{array}$ & Controls \\
\hline Number of subjects & 20344 & 197705 \\
\hline Age (years), mean $\pm S D$ & $78.6 \pm 8.1$ & $78.1 \pm 7.7$ \\
\hline Follow-up (years), mean $\pm S D$ & $4.2 \pm 3.5$ & $4.2 \pm 3.5$ \\
\hline Sex, \% men & 56.8 & 45.4 \\
\hline $\begin{array}{l}\text { Hospitalisation for pneumonia in year prior to } \\
\text { cohort entry, \% }\end{array}$ & 7.4 & 3.0 \\
\hline $\begin{array}{l}\text { Hospitalisation for COPD in year prior to index } \\
\text { date, } \%\end{array}$ & 14.6 & 4.2 \\
\hline $\begin{array}{l}\text { Number of hospitalisations for COPD in year prior } \\
\text { to index date }(\text { mean } \pm S D)\end{array}$ & $0.2 \pm 0.6$ & $0.1 \pm 0.3$ \\
\hline \multicolumn{3}{|c|}{ Respiratory medication use in the year prior to index date } \\
\hline $\begin{array}{l}\text { Oral corticosteroids (no. of prescriptions), } \\
\text { mean } \pm \text { SD }\end{array}$ & $1.4 \pm 4.3$ & $0.5 \pm 2.7$ \\
\hline Antibiotics (no. of prescriptions), mean \pm SD & $1.2 \pm 3.9$ & $0.5 \pm 2.4$ \\
\hline $\begin{array}{l}\text { Respiratory drugs (no. of prescriptions), } \\
\text { mean } \pm \text { SD }\end{array}$ & $10.1 \pm 11.1$ & $5.9 \pm 8.1$ \\
\hline Short-acting $\beta$ agonists, $\%$ & 77.8 & 60.5 \\
\hline Short-acting anticholinergics, \% & 52.5 & 31.2 \\
\hline Long-acting $\beta$ agonists, $\%$ & 21.1 & 14.6 \\
\hline Long-acting anticholinergics, \% & 2.7 & 1.4 \\
\hline Theophylline, \% & 14.0 & 11.3 \\
\hline \multicolumn{3}{|c|}{ Other medication use in the year prior to index date } \\
\hline Cardiac drugs, \% & 79.7 & 76.6 \\
\hline Diabetes drugs, \% & 17.3 & 14.4 \\
\hline Antidepressants, \% & 21.9 & 17.6 \\
\hline Central nervous system drugs, \% & 62.5 & 54.4 \\
\hline Osteoporosis drugs, \% & 16.2 & 15.4 \\
\hline NSAIDs, \% & 26.4 & 29.8 \\
\hline Narcotics, \% & 23.8 & 16.8 \\
\hline Antirheumatic drugs, \% & 1.2 & 0.9 \\
\hline
\end{tabular}


Table 2 Characteristics of controls selected from cohort of patients with COPD, according to current use of fluticasone and budesonide

\begin{tabular}{|c|c|c|c|}
\hline & Non-use & Fluticasone & Budesonide \\
\hline Number of subjects & 120890 & 24198 & 9542 \\
\hline Age (years), mean $\pm S D$ & $78.5 \pm 7.7$ & $78.1 \pm 7.9$ & $76.9 \pm 7.4$ \\
\hline Follow-up (years), mean $\pm S D$ & $4.3 \pm 3.6$ & $4.5 \pm 3.7$ & $4.2 \pm 3.5$ \\
\hline Sex, \% men & 44.9 & 47.5 & 47.6 \\
\hline $\begin{array}{l}\text { Hospitalisation for pneumonia in year } \\
\text { prior to cohort entry, } \%\end{array}$ & 2.9 & 3.5 & 2.1 \\
\hline $\begin{array}{l}\text { Hospitalisation for COPD in year prior } \\
\text { to index date, } \%\end{array}$ & 2.1 & 9.4 & 4.7 \\
\hline $\begin{array}{l}\text { Number of hospitalisations for COPD } \\
\text { in year prior to index date (mean } \pm \text { SD) }\end{array}$ & $0.0 \pm 0.2$ & $0.1 \pm 0.4$ & $0.1 \pm 0.3$ \\
\hline \multicolumn{4}{|c|}{ Respiratory medication use in year prior to index date } \\
\hline $\begin{array}{l}\text { Oral corticosteroids (no. of } \\
\text { prescriptions), mean } \pm \text { SD }\end{array}$ & $0.4 \pm 2.6$ & $0.9 \pm 3.0$ & $0.9 \pm 2.9$ \\
\hline $\begin{array}{l}\text { Antibiotics (no. of prescriptions), } \\
\text { mean } \pm \text { SD }\end{array}$ & $0.3 \pm 2.4$ & $0.8 \pm 2.7$ & $0.8 \pm 2.7$ \\
\hline $\begin{array}{l}\text { Respiratory drugs (no. of } \\
\text { prescriptions), mean } \pm S D\end{array}$ & $4.2 \pm 7.0$ & $10.6 \pm 9.6$ & $9.6 \pm 9.4$ \\
\hline Short-acting $\beta$ agonists, \% & 44.1 & 89.3 & 79.4 \\
\hline Short-acting anticholinergics, \% & 24.5 & 57.9 & 25.9 \\
\hline Long-acting $\beta$ agonists, $\%$ & 10.4 & 24.8 & 35.7 \\
\hline Long-acting anticholinergics, \% & 1.1 & 2.5 & 2.9 \\
\hline Theophylline, \% & 11.9 & 7.0 & 10.3 \\
\hline \multicolumn{4}{|l|}{$\begin{array}{l}\text { Other medication use in the year prior } \\
\text { to index date }\end{array}$} \\
\hline Cardiac drugs, \% & 76.0 & 80.7 & 76.3 \\
\hline Diabetes drugs, \% & 14.9 & 15.0 & 11.1 \\
\hline Antidepressants, \% & 17.2 & 20.6 & 16.6 \\
\hline Central nervous system drugs, \% & 54.3 & 55.7 & 51.9 \\
\hline Osteoporosis drugs, \% & 14.6 & 20.9 & 17.7 \\
\hline NSAIDs, \% & 29.9 & 27.7 & 29.3 \\
\hline Narcotics, \% & 16.1 & 18.6 & 16.2 \\
\hline Antirheumatic drugs, \% & 0.9 & 0.9 & 0.9 \\
\hline
\end{tabular}

budesonide users, but similar with respect to the amount of respiratory medication use.

Table 3 shows that, after adjustment for differences in the covariates, current use of ICS is associated with a $69 \%$ increase in the rate of serious pneumonia ( $\mathrm{RR} 1.69 ; 95 \%$ CI 1.63 to $1.75)$. The increase in the rate rises with the dose, ranging from $24 \%$ for the lower doses (RR 1.24 ; $95 \%$ CI 1.13 to 1.36 ) to $86 \%$ with the highest doses of ICS, equivalent to fluticasone $1000 \mathrm{mg}$ per day or more (RR 1.86 ; 95\% CI 1.77 to 1.94 ). Figure 2 displays the smoothed dose-response curves for the risk of serious pneumonia as a function of ICS dose measured in fluticasone equivalents. Table 3 also shows, by the results for past use, that these rates wane gradually after stopping ICS, practically vanishing after 6 months.

Table 4 shows that current use of fluticasone is associated with a twofold increase in the rate of serious pneumonia (RR 2.01 ; $95 \%$ CI 1.93 to 2.10 ), with a dose-response increase in the rate. However, current use of budesonide is associated with a $17 \%$ increase in the rate of serious pneumonia (RR $1.17 ; 95 \%$ CI 1.09 to 1.26 ), while the other ICS group that includes primarily beclomethasone presents a $41 \%$ increase. Figure 3 displays the smoothed dose-response curves for fluticasone and budesonide. Figure 4 shows that the effect of ICS peaks in the first year of use and remains elevated and stable over the long term, even up to 5 years of continuous use. Table 5 displays the sensitivity analyses stratifying the effects of fluticasone and budesonide by prior COPD hospitalisation, showing that the results remain consistent.

\section{DISCUSSION}

Using a large population-based cohort of over 160000 patients with COPD followed for up to 18 years, we found that ICS use is associated with a significant $69 \%$ increase in the risk of serious pneumonia, requiring hospitalisation or fatal. This risk was particularly increased with fluticasone, with a doubling of the rate, and dose dependent with doses of $1000 \mu \mathrm{g}$ of fluticasone per day associated with a 122\% increase. The risk with budesonide was comparatively much lower with an increase of $17 \%$ and no dose-response effect. These elevated risks disappeared within a few months of stopping the use of ICS.

Systemic corticosteroids have been associated with increased risks of pneumonia in patients with rheumatoid arthritis. ${ }^{26} 27 \mathrm{In}$ these patients, a dose-response increase in the risk of pneumonia was seen with doses of prednisone as low as $\leq 5 \mathrm{mg} /$ day $(\mathrm{RR}$ $1.4 ; 95 \%$ CI 1.1 to 1.6$),{ }^{26}$ and as low as $7.5 \mathrm{mg}$ or less (RR 2.3 ; $95 \%$ CI 1.2 to 4.4$).{ }^{27}$ It is then not unexpected that high doses of ICS have similar effects on the incidence of

Table 3 Crude and adjusted rate ratios of serious pneumonia associated with current use, dose and past use of inhaled corticosteroids among patients with COPD

\begin{tabular}{|c|c|c|c|c|c|}
\hline Inhaled corticosteroid exposure & Pneumonia cases & Controls & Crude rate ratio & Adjusted* rate ratio & $95 \% \mathrm{Cl}$ \\
\hline Number of subjects & 20344 & 197705 & & & \\
\hline No use in the year prior to index date, $\%$ & 46.47 & 61.15 & 1.00 & 1.00 & Reference \\
\hline Current use, $\% \dagger$ & 37.53 & 22.01 & 2.30 & 1.69 & 1.63 to 1.75 \\
\hline Low doseł & 3.12 & 2.72 & 1.50 & 1.24 & 1.13 to 1.36 \\
\hline Medium dose & 16.28 & 10.28 & 2.15 & 1.66 & 1.59 to 1.74 \\
\hline High dose & 18.14 & 9.01 & 2.73 & 1.86 & 1.77 to 1.94 \\
\hline Past use, $\%$ & 16.00 & 16.84 & 1.28 & 1.15 & 1.10 to 1.20 \\
\hline \multicolumn{6}{|l|}{ Time since stopping, \% } \\
\hline $61-180$ days & 9.95 & 9.96 & 1.35 & 1.19 & 1.13 to 1.26 \\
\hline $181-270$ days & 3.29 & 3.76 & 1.17 & 1.08 & 0.99 to 1.17 \\
\hline $271-365$ days & 2.76 & 3.11 & 1.19 & 1.08 & 0.99 to 1.18 \\
\hline
\end{tabular}

${ }^{*}$ Adjusted for all of the factors listed in table 1.

tCurrent use refers to a prescription of any one of inhaled fluticasone, budesonide, beclomethasone, flunisolide or triamcinolone in the 60 days prior to the index date. $\neq$ Current daily dose in fluticasone equivalents, in $\mu \mathrm{g} /$ day; high: 1000 or more; moderate: $500-999$; low: less than 500 .

COPD, chronic obstructive pulmonary disease. 
Figure 2 Dose-response curve for the rate ratio (solid line) and $95 \% \mathrm{Cls}$ (dashed lines) of pneumonia as a function of inhaled corticosteroid dose in $\mu \mathrm{g}$ (measured in fluticasone equivalents) estimated by cubic splines model fit by conditional logistic regression.

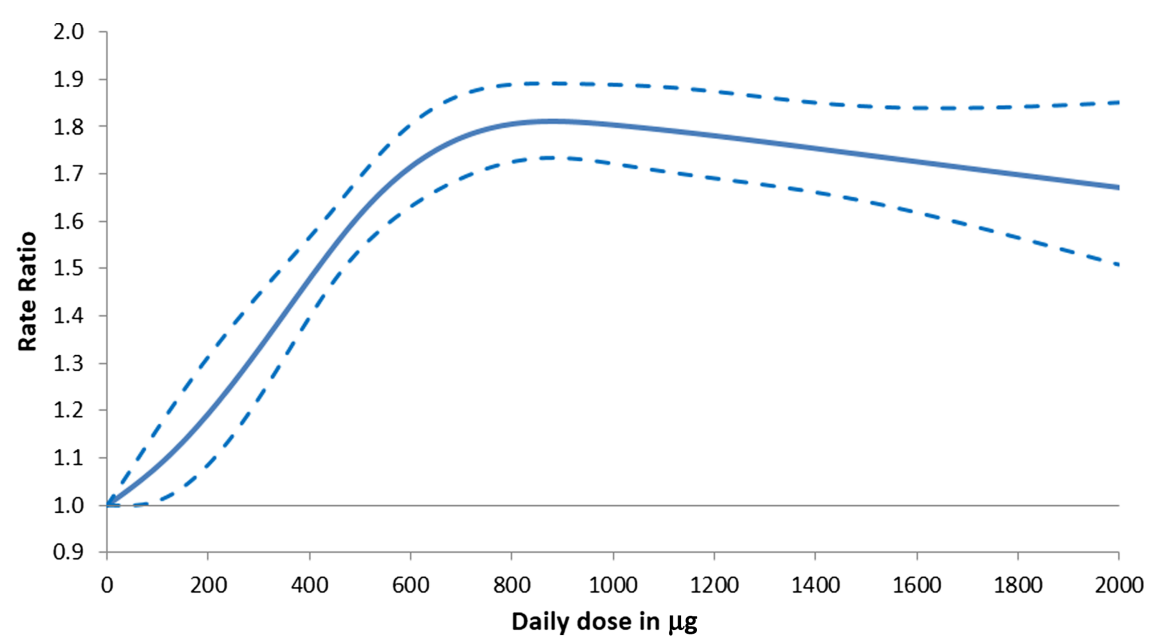

pneumonia, as $1000 \mu \mathrm{g}$ of inhaled fluticasone is estimated to be equivalent to $10 \mathrm{mg}$ per day of prednisone with systemic effects evaluated by suppression of serum cortisol. ${ }^{7}$

Our findings confirm the observations of several randomised trials of varying durations and doses. The 2-year INSPIRE and 3-year TORCH trials both studied high doses of fluticasone (1000 $\mu \mathrm{g}$ per day) and found HRs of pneumonia of 1.94 (95\% CI 1.19 to 3.17 ) and 1.64 (95\% CI 1.33 to 2.02), respectively, ${ }^{3} 1314$ A 1-year trial of fluticasone $1000 \mu \mathrm{g} / \mathrm{day}$ found a higher increase in the risk (RR 3.1; 95\% CI 1.3 to 7.3 ; our calculation), ${ }^{15}$ which is consistent with our findings of a somewhat higher early risk. Our results confirm the subgroup analyses of the meta-analysis, suggesting that the risk is particularly elevated with high doses and start at short durations of use. ${ }^{12}$ With respect to the effect of dose, the two trials that evaluated a lower dose of fluticasone $(500 \mu \mathrm{g}$ per day) for 1 year also found a close to twofold higher incidence of pneumonia at 1 year with fluticasone. ${ }^{16-18}$ This is also consistent with the dose-response curve from our study, which shows an increase in risk with lower doses and a RR of 1.6 at $500 \mu \mathrm{g} /$ day of fluticasone.

The findings for budesonide confirm the pooled analysis of several trials of budesonide that found no increased risk of pneumonia over 1 year (RR 1.05 ; 95\% CI 0.81 to 1.37 ), ${ }^{19}$ and a meta-analysis that suggests a lower risk with budesonide compared with fluticasone. ${ }^{20}$ Our finding of a more moderate $17 \%$ increase in the rate of serious pneumonia is concordant with these trial data. Moreover, the risk of pneumonia did not increase with the dose of budesonide. Nevertheless, a concern found increases in pneumonia adverse events with daily doses of $640 \mu \mathrm{g}$ (RR 2.3; 95\% CI 1.2 to 4.7) and $320 \mu \mathrm{g}$ (RR 1.7; 95\% CI 0.8 to 3.6), equivalent to $400 \mu \mathrm{g}$ and $200 \mu \mathrm{g}$ of fluticasone, respectively. ${ }^{28}$ Since the fluticasone-salmeterol combination was approved and therefore promoted for COPD during the time period under study while the budesonide-formoterol combination was not, it remains possible that those receiving remains with budesonide as a recent 1-year trial in COPD

Table 4 Crude and adjusted rate ratios of serious pneumonia associated with current use and dose of the different ICS among patients with COPD

\begin{tabular}{|c|c|c|c|c|c|}
\hline ICS exposure & Cases & Controls & Crude rate ratio & Adjusted* rate ratio & $95 \% \mathrm{Cl}$ \\
\hline Number of subjects & 20344 & 197705 & & & \\
\hline No use in the year prior to index date, $\%$ & 46.47 & 61.15 & 1.00 & 1.00 & Reference \\
\hline \multicolumn{6}{|l|}{ Fluticasone } \\
\hline Current use, $\% \dagger$ & 24.53 & 12.24 & 2.79 & 2.01 & 1.93 to 2.10 \\
\hline Low doseł & 0.37 & 0.32 & 1.61 & 1.46 & 1.15 to 1.87 \\
\hline Medium dose & 11.30 & 6.50 & 2.42 & 1.87 & 1.77 to 1.97 \\
\hline High dose & 12.86 & 5.42 & 3.31 & 2.22 & 2.10 to 2.34 \\
\hline \multicolumn{6}{|l|}{ Budesonide } \\
\hline Current use, \% & 5.17 & 4.83 & 1.45 & 1.17 & 1.09 to 1.26 \\
\hline Low dose & 0.33 & 0.37 & 1.21 & 1.05 & 0.81 to 1.36 \\
\hline Medium dose & 2.65 & 2.42 & 1.49 & 1.23 & 1.12 to 1.35 \\
\hline High dose & 2.18 & 2.03 & 1.45 & 1.13 & 1.02 to 1.26 \\
\hline \multicolumn{6}{|l|}{ Other ICS§ } \\
\hline Current use, $\%$ & 7.84 & 4.95 & 2.01 & 1.41 & 1.33 to 1.51 \\
\hline Low dose & 2.41 & 2.03 & 1.49 & 1.20 & 1.09 to 1.33 \\
\hline Medium dose & 2.33 & 1.35 & 2.21 & 1.52 & 1.37 to 1.69 \\
\hline High dose & 3.10 & 1.56 & 2.53 & 1.57 & 1.43 to 1.73 \\
\hline
\end{tabular}

${ }^{*}$ Adjusted for all of the factors listed in table 1 .

tCurrent use refers to a prescription in the 60 days prior to the index date.

$\ddagger$ Current daily dose in fluticasone equivalents, in $\mu \mathrm{g} /$ day; high: 1000 or more; moderate: 500-999; low: less than 500 .

$\S$ Beclomethasone, flunisolide or triamcinolone.

COPD, chronic obstructive pulmonary disease; ICS, inhaled corticosteroid. 
Figure 3 Dose-response curves for the rate ratio (solid lines) and $95 \% \mathrm{Cls}$ (dashed lines) of pneumonia as a function of inhaled fluticasone (blue lines) and budesonide (red lines) dose in $\mu \mathrm{g}$ (measured in fluticasone equivalents) estimated by cubic splines model fit by conditional logistic regression.

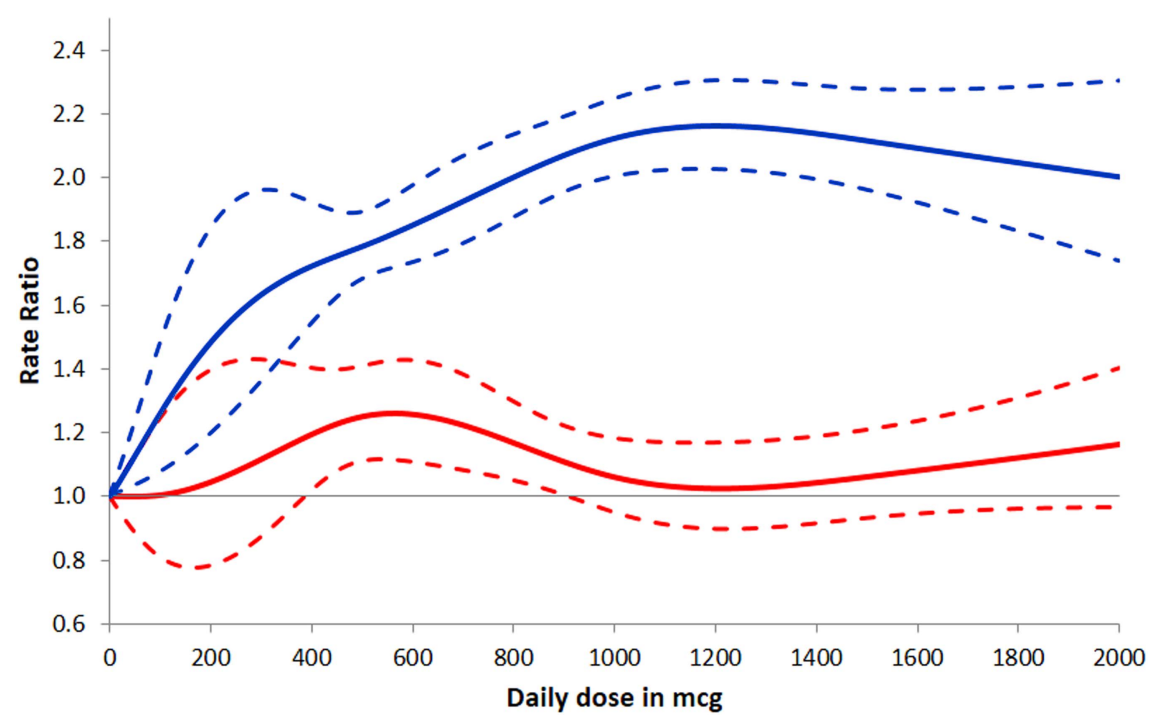

the budesonide combination were more likely to have asthma rather than COPD and be at lower risk of pneumonia compared with subjects receiving the fluticasone-salmeterol combination. Furthermore, since a higher dose formulation was only available for the fluticasone-salmeterol combination, patients with more severe disease may have been more likely to have received a combination therapy containing fluticasone rather than budesonide. Therefore, data on this question from countries where budesonide has a greater market share would be a valuable addition to this evidence.

There is good evidence supporting the effect of ICS on human pulmonary host defence, acting through several biological pathways, such as an inhibitory action on macrophage functions, a decrease in cytokine production and nitric oxide expression, which may lead to a failure to control infection. ${ }^{29} 30$ Although there have been no studies directly comparing the effects of fluticasone and budesonide on host defence, differences are likely related to their contrasting pharmacokinetic and pharmacodynamic properties. Fluticasone is known to be more potent (ie, greater effect on intracellular steroid receptors), more lipophilic and has a longer half life than budesonide. ${ }^{29}$ Accordingly, fluticasone has a better penetration at the site of action and a more prolonged effect. It is therefore not surprising that a greater risk of oropharyngeal side effects is found with fluticasone compared with budesonide. ${ }^{31}$ While high potency and lipophilicity can be positive features allowing a lower dose to exert the desired effect, these characteristics may adversely affect drug safety. Indeed, a more prolonged corticosteroid effect in the lungs and greater pulmonary retention will facilitate the local immunosuppressive action. ${ }^{32} 33$ Budesonide enters the lungs with a lower lipophilicity, dissolves more quickly into pulmonary fluids, leading to a reduced local effect because of a more rapid cleavage and passage into the systemic circulation. ${ }^{30}$

This study has strengths and some limitations. The size of the population-based cohort of over 160000 patients observed over 18 years permitted the identification of over 20000 cases of serious pneumonia, allowing precise estimates of the risk associated with the different ICS at several doses. In this study, we defined serious pneumonia as a hospitalisation with a primary diagnosis of pneumonia or death from pneumonia, but did not have proof that the diagnosis was based on radiographic findings as these are not recorded in the RAMQ databases. However, it is most likely that as a primary inpatient diagnosis, it was in fact supported by a radiographic finding. To address confounding by
Figure 4 Rate ratio (solid line) and $95 \% \mathrm{Cls}$ (dashed lines) of pneumonia as a function of the duration of current inhaled corticosteroid use estimated by cubic splines model fit by conditional logistic regression.

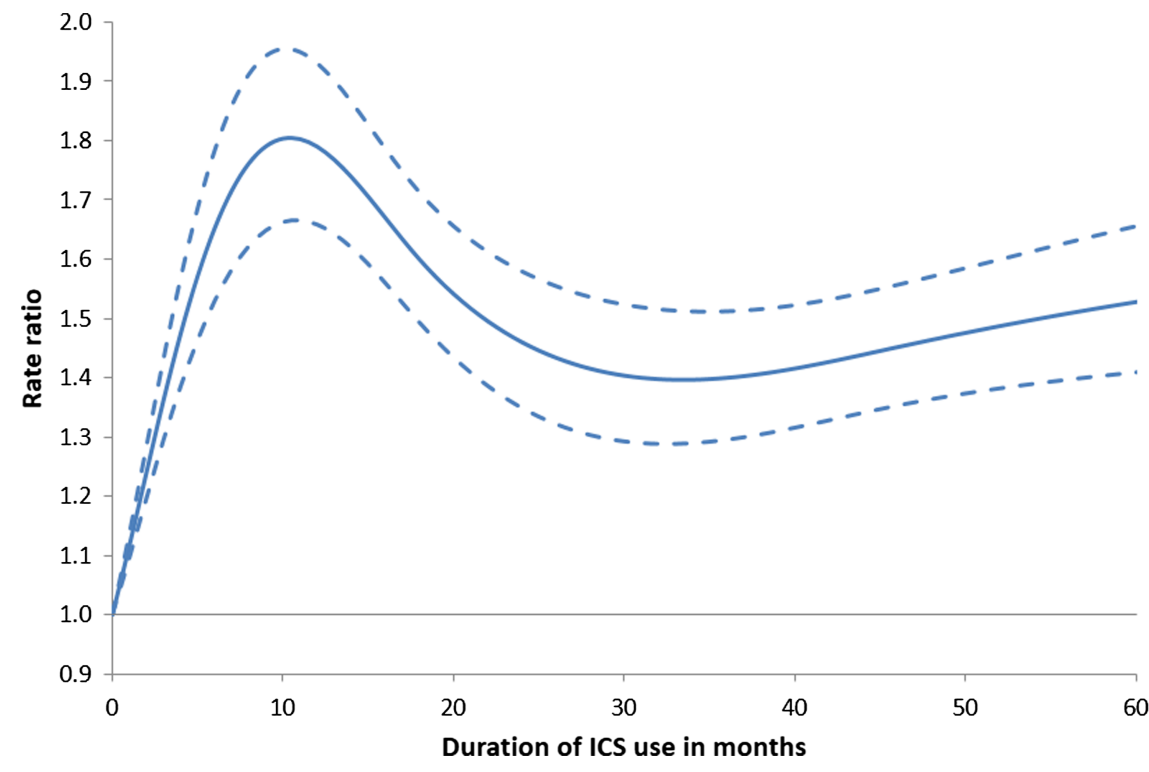


Table 5 Crude and adjusted rate ratios of serious pneumonia associated with current use of fluticasone and budesonide, stratified by prior COPD hospitalisation

\begin{tabular}{|c|c|c|c|c|c|}
\hline ICS exposure & Cases & Controls & Crude rate ratio & Adjusted* rate ratio & $95 \% \mathrm{Cl}$ \\
\hline \multicolumn{6}{|l|}{ Prior COPD hospitalisation } \\
\hline Number of subjects & 2975 & 8249 & & & \\
\hline No use, $\% \dagger$ & 23.03 & 30.56 & 1.00 & 1.00 & Reference \\
\hline Fluticasone current use, $\% \ddagger$ & 39.36 & 27.48 & 1.96 & 1.75 & 1.56 to 1.97 \\
\hline Budesonide current use, \%‡ & 5.71 & 5.32 & 1.39 & 1.19 & 0.97 to 1.47 \\
\hline \multicolumn{6}{|l|}{ No prior COPD hospitalisation } \\
\hline Number of subjects & 17369 & 189456 & & & \\
\hline No use, \% & 50.48 & 62.48 & 1.00 & 1.00 & Reference \\
\hline Fluticasone current use, $\% \ddagger$ & 21.99 & 11.58 & 2.47 & 2.01 & 1.92 to 2.10 \\
\hline Budesonide current use, \%‡ & 5.07 & 4.80 & 1.34 & 1.14 & 1.06 to 1.23 \\
\hline
\end{tabular}

COPD severity, we adjusted for the number of prescriptions for respiratory medications other than ICS, and for exacerbations as measured by prescriptions for oral corticosteroids, antibiotics, as well as prior hospitalisations for pneumonia and COPD exacerbation. Yet, residual confounding arising from unmeasured covariates can still be present. Of most concern is the possibility that budesonide may have been preferentially prescribed to patients with a lower risk of pneumonia, such as those with asthma or less severe COPD. In this specific study, however, our main results, adjusted for differences in severity, are consistent with those of several randomised trials which are inherently free of confounding, albeit less powerful with smaller study populations. Exposure to ICS was measured from dispensed prescriptions so that one must assume that the drugs were actually taken. However, not taking these medications would actually tend to underestimate the true risk increase. The definition of COPD used to identify the patients in our cohort was not based on a physician diagnosis of COPD or objective criteria for the diagnosis of COPD, but rather on including only subjects who started using respiratory medications at the age of 55 years or later and excluding subjects with a prior asthma hospitalisation or who used asthma-specific medications such as nedocromil, ketotifen, cromolyn or antileukotrienes. Nevertheless, our definition likely captured some patients with asthma. One can expect that this would reduce the estimate of risk of ICS since ICS do not appear to increase the risk of pneumonia in patients with asthma. ${ }^{34}$ Our sensitivity analysis within subjects previously hospitalised for COPD found practically the same differences in estimates of risk for fluticasone and budesonide.

The dose-response effect with fluticasone that we found on the incidence of serious pneumonia, sustained over a long time, is important in the risk-benefit balance for patients with COPD. While ICS are clearly effective for the treatment of asthma, their effectiveness in treating COPD is still controversial. ${ }^{12}$ The fact that ICS are now commonly combined in a single device with a long-acting bronchodilator, the latter recommended earlier in COPD, has resulted in ICS now being used by over $70 \%$ of patients with COPD. ${ }^{2}$ Moreover, these combined medications most often contain high doses of ICS, as high as $1000 \mu \mathrm{g}$ of fluticasone per day. ${ }^{3}{ }^{4}$ Consequently, the widespread use of ICS at higher doses in patients with COPD, along with the elevated incidence of pneumonia in this age group and their uncertain effectiveness, impact on the risk-benefit profile of ICS in COPD.
In conclusion, high and low doses of fluticasone in patients with COPD are associated with an important increase in the risk of serious pneumonia, while the risk with budesonide is comparatively low, even at high doses, though it needs further examination in light of recent data and the possibility that patients receiving budesonide are inherently at lower risk of pneumonia than those prescribed fluticasone. Further investigations into why the two popular ICS fluticasone and budesonide have such different effects on the risk of pneumonia are warranted.

Acknowledgements The authors thank the Commission d'accès à l'information du Québec for allowing access to the data and agents from the Régie de l'assurance maladie du Québec (RAMQ) for providing the database.

Contributors SS acquired the data. SS, VP and PE participated in the analysis. SS, $\mathrm{FL}$ and PE wrote the article. All authors had full access to the data and SS is guarantor for the overall content.

Funding This research was funded in part by a grant from the Canadian Institutes of Health Research (CIHR) and the Canadian Foundation for Innovation (CFI). SS is the recipient of the James McGill Chair award. The funding agencies were not involved in the study design, data analysis and interpretation, or the preparation of the manuscript.

Competing interests SS has participated in advisory meetings or as conference speaker for AstraZeneca, Boehringer-Ingelheim, Forest, GlaxoSmithKline, Merck, Novartis, Nycomed and Pfizer. PE has received speaker fees and attended advisory boards for AstraZeneca, Boehringer-Ingelheim, GlaxoSmithKline, Merck, Novartis, and Nycomed.

Provenance and peer review Not commissioned; internally peer reviewed.

Open Access This is an Open Access article distributed in accordance with the Creative Commons Attribution Non Commercial (CC BY-NC 3.0) license, which permits others to distribute, remix, adapt, build upon this work non-commercially, and license their derivative works on different terms, provided the original work is properly cited and the use is non-commercial. See: http://creativecommons.org/ licenses/by-nc/3.0/

\section{REFERENCES}

1 Postma DS, Calverley P. Inhaled corticosteroids in COPD: a case in favour. Eur Respir J 2009;34:10-12.

2 Suissa S, Barnes PJ. Inhaled corticosteroids in COPD: the case against. Eur Respir J 2009:34:13-16.

3 Calverley PM, Anderson JA, Celli B, et al. Salmeterol and fluticasone propionate and survival in chronic obstructive pulmonary disease. N Engl J Med 2007:356:775-89.

4 Wedzicha JA, Calverley PM, Seemungal TA, et al. The prevention of chronic obstructive pulmonary disease exacerbations by salmeterol/fluticasone propionate or tiotropium bromide. Am J Respir Crit Care Med 2008;177:19-26.

5 Garbe E, LeLorier J, Boivin JF, et al. Inhaled and nasal glucocorticoids and the risks of ocular hypertension or open-angle glaucoma. JAMA 1997;277:722-7. 
6 Garbe E, Suissa S, LeLorier J. Association of inhaled corticosteroid use with cataract extraction in elderly patients [published erratum appears in JAMA 1998 Dec 2;280 (21):1830] [see comments]. JAMA 1998;280:539-43.

7 Lipworth BJ. Systemic adverse effects of inhaled corticosteroid therapy: a systematic review and meta-analysis. Arch Intern Med 1999:159:941-55.

8 Kelly HW, Nelson HS. Potential adverse effects of the inhaled corticosteroids. J Allergy Clin Immunol 2003;112:469-78.

9 Ernst P, Gonzalez AV, Brassard P, et al. Inhaled corticosteroid use in chronic obstructive pulmonary disease and the risk of hospitalization for pneumonia. Am J Respir Crit Care Med 2007;176:162-6.

10 Suissa S, Kezouh A, Ernst P. Inhaled corticosteroids and the risks of diabetes onset and progression. Am J Med 2010;123:1001-6.

11 Singh S, Amin AV, Loke YK. Long-term use of inhaled corticosteroids and the risk of pneumonia in chronic obstructive pulmonary disease: a meta-analysis. Arch Intern Med 2009;169:219-29.

12 Drummond MB, Dasenbrook EC, Pitz MW, et al. Inhaled corticosteroids in patients with stable chronic obstructive pulmonary disease: a systematic review and meta-analysis. JAMA 2008;300:2407-16.

13 Crim C, Calverley PM, Anderson JA, et al. Pneumonia risk in COPD patients receiving inhaled corticosteroids alone or in combination: TORCH study results. Eur Respir J 2009:34:641-7.

14 Calverley PM, Stockley RA, Seemungal TA, et al. Reported pneumonia in patients with COPD: findings from the INSPIRE study. Chest 2011;139:505-12.

15 Kardos P, Wencker M, Glaab T, et al. Impact of salmeterol/fluticasone propionate versus salmeterol on exacerbations in severe chronic obstructive pulmonary disease. Am J Respir Crit Care Med 2007;175:144-9.

16 Ferguson GT, Anzueto A, Fei $R$, et al. Effect of fluticasone propionate/salmeterol (250/50 microg) or salmeterol (50 microg) on COPD exacerbations. Respir Med 2008;102:1099-108.

17 Anzueto A, Ferguson GT, Feldman G, et al. Effect of fluticasone propionate/salmeterol (250/50) on COPD exacerbations and impact on patient outcomes. COPD 2009;6:320-9.

18 Chowdhury BA. Summary review of regulatory action: fluticasone propionate and salmeterol. Silver Spring, MD: Division of Pulmonary and Allergy Products, CDER, FDA; 2008.

19 Sin DD, Tashkin D, Zhang $X$, et al. Budesonide and the risk of pneumonia: a meta-analysis of individual patient data. Lancet 2009;374:712-19.

20 Halpin DM, Gray J, Edwards SJ, et al. Budesonide/formoterol vs. salmeterol/ fluticasone in COPD: a systematic review and adjusted indirect comparison of pneumonia in randomised controlled trials. Int J Clin Pract 2011 65:764-74.
21 Singh S, Loke YK. Risk of pneumonia associated with long-term use of inhaled corticosteroids in chronic obstructive pulmonary disease: a critical review and update. Curr Opin Pulm Med 2010;16:118-22.

22 Ernst $\mathrm{P}$, Baltzan $\mathrm{M}$, Deschenes J, et al. Low-dose inhaled and nasal corticosteroid use and the risk of cataracts. Eur Respir J 2006;27:1168-74.

23 Suissa S, Baltzan M, Kremer R, et al. Inhaled and nasal corticosteroid use and the risk of fracture. Am J Respir Crit Care Med 2004;169:83-8.

24 National Asthma and Prevention Program. Guidelines for the diagnosis and management of asthma. Expert Panel Report 2. Bethesda, MD: National Heart Lung and Blood Institute; 1997, NIH Publication No. 97-4051.

25 Boulet LP, Becker A, Berube D, et al. Canadian asthma consensus report, 1999 Can Med Assoc J 1999;161:s1-61.

26 Wolfe F, Caplan L, Michaud K. Treatment for rheumatoid arthritis and the risk of hospitalization for pneumonia: associations with prednisone, disease-modifying antirheumatic drugs, and anti-tumor necrosis factor therapy. Arthritis Rheum 2006;54:628-34

27 Grijalva CG, Kaltenbach L, Arbogast PG, et al. Initiation of rheumatoid arthritis treatments and the risk of serious infections. Rheumatology (Oxford) 2010;49:82-90.

28 Sharafkhaneh A, Southard JG, Goldman M, et al. Effect of budesonide/formoterol pMDI on COPD exacerbations: a double-blind, randomized study. Respir Med 2012;106:257-68

29 Patterson CM, Morrison RL, D'Souza A, et al. Inhaled fluticasone propionate impairs pulmonary clearance of Klebsiella Pneumoniae in mice. Respir Res 2012;13:40.

30 Hubner M, Hochhaus G, Derendorf H. Comparative pharmacology, bioavailability, pharmacokinetics, and pharmacodynamics of inhaled glucocorticosteroids. Immunol Allergy Clin North Am 2005;25:469-88.

31 Adams N, Bestall JM, Lasserson TJ, et al. Inhaled fluticasone versus inhaled beclomethasone or inhaled budesonide for chronic asthma. Cochrane Database Syst Rev 2004;(2):CD002310

32 Esmailpour N, Hogger $\mathrm{P}$, Rabe KF, et al. Distribution of inhaled fluticasone propionate between human lung tissue and serum in vivo. Eur Respir $J$ 1997:10:1496-9.

33 Thorsson L, Edsbacker S, Kallen A, et al. Pharmacokinetics and systemic activity of fluticasone via Diskus and pMDI, and of budesonide via Turbuhaler. $\mathrm{Br} J \mathrm{Clin}$ Pharmacol 2001;52:529-38.

34 O'Byrne PM, Pedersen S, Carlsson LG, et al. Risks of pneumonia in patients with asthma taking inhaled corticosteroids. Am J Respir Crit Care Med 2011;183:589-95. 